\title{
The Effect of Heat and Cryogenic Treatment on Wear Properties of 6061 Alloy
}

\author{
Shivakumara P, P L Srinivasa Murthy, Sunil Kumar K, Prasanna Rao
}

\begin{abstract}
The published information on ferrous and nonferrous metals especially Aluminium alloys subjected to deep cryogenic treatment (DCT) have yielded much improved mechanical, tribological and thermal properties resulting in improved properties in the field. Keeping the above aspects in view, tribological studies have been taken up in this work with the main objective of evaluating the wear resistance of the most used Aluminium alloys viz: Al 6061 samples at cryogenic temperature and subjected them to deep cryogenic treatment for temperature . The novelty of the work lies in conducting the wear test in cryogenic atmosphere which is the first of its kind as meagre report is available. It is observed from the wear data that the slide wear resistance and coefficient of friction evaluated in the laboratory conditions show superior wear resistance for the load application of $40 \mathrm{~N}$ and $50 \mathrm{~N}$ and lower friction levels for the samples subjected to sliding at cryogenic temperature as well as for the samples deeply cryo treated compared to the untreated ones. The data have been substantiated by Scanning Electron Microscopic features (SEM).
\end{abstract}

Keywords : AA 6061alloy, heat treatments, wear properties .

\section{INTRODUCTION}

Aluminium alloy 6061 is one of the most extensively used 6000 series aluminium alloys. It is a versatile heat treatable extruded alloy with medium to high strength capabilities. Aluminium alloys are divided into casting alloys and wrought alloys, and are best suited for different applications. Wrought aluminium alloys, such as the 6061 alloy, are worked by extruding, rolling or forging them into specified shapes. Some alloys can be heat-treated or cold-worked by different methods to increase their strength and hardness, corrosion resistance, ease of fabrication and other advantages. The common grades of commercial 6061 aluminium are 6061-0, 6061-T4, and 6061-T6, however, tempers up to -T9 are produced conditions and good corrosion resistance to sea water. This alloy also offers good finishing characteristics and responds well to anodizing, however, where cosmetic appearance is critical, consider the

Revised Manuscript Received on August 15, 2020.

* Correspondence Author

Shivakumara P*, Research scholar , Dept. Of Mechanical Engineering, MSRIT Bangalore, Karnataka,

P L Srinivasa murthy, Associate professor, Dept. Of Mechanical Engineering, MSRIT Bangalore, Karnataka,

Sunil Kumar K, Assistant professor, Dept. of Mechanical Engineering, RLJIT Doddaballapur, Karnataka, India

Prasanna Rao, Associate professor, Dept. Of Mechanical Engineering, MSRIT Bangalore, Karnataka

(C) The Authors. Published by Blue Eyes Intelligence Engineering and Sciences Publication (BEIESP). This is an open access article under the CC BY-NC-ND license (http://creativecommons.org/licenses/by-nc-nd/4.0/) use of alloy 6063. The most common anodizing methods include clear, clear and color dye, and hard coat. Alloy 6061can be easily welded and joined by various commercial methods. (Caution: direct contact by dissimilar metals can cause galvanic corrosion.) Since 6061 is a heat-treatable alloy, strength in its -T6 condition can be reduced in the weld region. Selection of an appropriate filler alloy will depend on the desired weld characteristics. Consult the Material Safety Data Sheet (MSDS) for proper safety and handling precautions when using alloy 6061. 6061-T6 aluminium is structurally stronger and more useful in the manufacturing of durable products. It is commonly used in aircraft construction. Although primarily used in private rather than commercial aircraft, its strength-to-weight ratio is very high, making it ideal for large parts that need to be very light, such as the plane's fuselage and wings. This light weight also made 6061-T6 aluminum the best choice for the famous gold-anodized plaques that were mounted on board the 1972 Pioneer 10 and 1973 Pioneer 11 spacecraft. Aluminum in its purest form is too soft and reactive to be of structural use. However, its alloys, such as 6061-T6 alloy, make it structurally stronger and more useful in the manufacturing of durable products. 6061-T6 aluminum is commonly used in aircraft construction. Although primarily used in private rather than commercial aircraft, its strength-to-weight ratio is very high, making it ideal for large parts that need to be very light, such as the plane's fuselage and wings. This light weight also made 6061-T6 aluminum the best choice for the famous gold-anodized plaques that were mounted on board the 1972 Pioneer 10 and 1973 Pioneer 11 spacecraft. 6061-T6 aluminum properties make it a material of choice for builders of boats and water-craft because it's strong and lightweight. It is ideal for sailboat masts and for hulls of larger yachts that cannot be made from fiberglass. Small, flat-bottom canoes are almost entirely fabricated from 6061-T6, although the bare aluminum is often coated with protective epoxy to improve its resistance to corrosion.

\section{REVIEW CRITERIA}

It is observed thatAluminium alloy 6061 (AA 6061)

finds various usage as structural material

Adnan N. Abood [1] The investigation of Low Cycle Fatigue (LCF) of aluminum alloy AA6061 in three conditions, annealing (O), T4 and T651. AA6061-O has the higher value of transition fatigue life (NT) because it has the highest ductility.

M. E. Kassner[2], in his study investigate the quench sensitivity of the mechanical properties of 6061 and 6069 aluminum alloys.

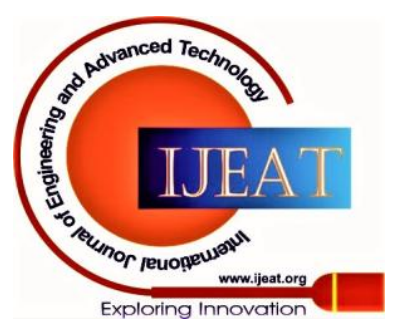


The relationship between mechanical properties and quench delay time at various temperatures between $200-500^{\circ} \mathrm{C}$ was determined. It was concluded that the 6069-T6 was somewhat more quench sensitive than 6061, increased data on the quench sensitivity of the traditional alloy, 6061-T6

Z. Nikseresht, [3] In his research, the corrosion behaviour and microstructure of Al6061 alloy welded by GTAW (Gas tungsten arc welding) and followed by various heat treatments have been investigated.

improvement of corrosion resistance of AA6061 alloy in seawater. Gravimetric, potentio dynamic polarization, linear polarization resistance and electrochemical impedance measurements were employed

R. Rosliza, W.B. Wan Nik [4]in their studies examine the use of tapioca starch for to study the corrosion behavior of AA6061 alloy in seawater.

Mike Meierin [5] his review paper on 6061-T651 alloy is the most popular 6000 series alloy. It has moderate strength but excellent weld ability compared to other heat treatable alloys, excellent corrosion resistance and a high plane strain fracture toughness. 6061 will age naturally to an essentially stable T4 condition.

A. B. Gurcan T.N. Baker[7] his study investigated the wear resistance of four AA6061 MMCs together with the monolithic AA6061 alloy, all in the T6 condition.

Masoud I. M., [10] In his investigation the effect of aging time and temperatures on the mechanical properties of 6061 Aluminum alloy has been studied. After $4 \mathrm{~h}$ solution treatment at $530^{\circ} \mathrm{C}$ followed by water quenching the 6061 Aluminum specimens were aged at 145, 165,185,

Chee-Fai Tan [11] The work determine the effects of artificial ageing on the strength of 6061-T6 aluminum alloy. The precipitation hardening undergoes a thermal treatment, which consists of heat treatment, quenching process and artificial ageing. The study focused on artificial ageing temperature between $175^{\circ} \mathrm{C}$ to $420^{\circ} \mathrm{C}$ at different period of time. The study leads to the conclusion that the optimum aged can be achieved within $175^{\circ} \mathrm{C}$ to $195^{\circ} \mathrm{C}$ at 2 to 6 hours ageing time.

Volker Franco Steier [12] In his work evaluate the effect of a deep cryogenic treatment on the wear behavior and on the microstructure of an aluminum alloy. The wear behavior was investigated using micro abrasive wear tests. The cryogenic treated specimens proved to have similar low wear rates as the specimens coated with $\mathrm{CrN}$. The most distinct improvement was reached with a combination of both techniques .

Nurulhilmi Zaiedah [13] He investigated the effect of heat treatment on mechanical properties and microstructure of 6061 aluminium alloy. The aluminium alloys were examined in the heat treated conditions, using different quenching media, water and oil. The alloy was solution heat treated at temperature of $529^{\circ} \mathrm{C}$ for one, three and five hour respectively. Aging treatment was carried out at temperature of $160^{\circ} \mathrm{C}$ which is assumed to be the best temperature for ageing process. The results shows hardness and impact strength are inversely proportional to each other, as the hardness of 6061 aluminium alloy decreases and impact strength increases
O. K. Abubakre [14] Specimens of 6061 Aluminum alloy were prepared and quenched in water, sheanut oil and palm oil at temperature of $400^{\circ} \mathrm{C}, 450^{\circ} \mathrm{C}$ and $530^{\circ} \mathrm{C}$ to determine the effect of variation in temperature and quenching media on some mechanical properties and the microstructure of the alloy. The results showed that the specimen heat-treated to $530^{\circ} \mathrm{C}$ and quenched in water has the highest tensile strength of $109 \mathrm{~N} / \mathrm{mm}^{2}$ and yield strength of $70.89 \mathrm{~N} / \mathrm{mm}^{2}$. The specimen heated at $530^{\circ} \mathrm{C}$ and quenched in water gave the highest value of 35.50 in hardness (HRC). The toughness property of the alloy, as indicated by Charpy impact values, is better at $530^{\circ} \mathrm{C}$ for specimen quenched in she-anut oil and least impact strength is observed in specimen quenched in water at $400^{\circ} \mathrm{C}$

In the trial contemplates, the AA7075 aluminum compound that is usually utilized in the part of room and aviation inferable from its particular weight, high quality, electrical and warm conductivities was utilized in the test thinks about. Concoction creation of the AA7075 amalgam utilized in the exploratory investigations is given in the Table.

3.0 Chemical composition 6065

\begin{tabular}{|l|l|}
\hline Elements & Composition \\
\hline $\mathrm{Si}$ & $0.4-0.8$ \\
\hline $\mathrm{Fe}$ & $0.7 \mathrm{Max}$ \\
\hline $\mathrm{Cu}$ & $0.15-0.40$ \\
\hline $\mathrm{Mn}$ & $0.15 \mathrm{max}$ \\
\hline $\mathrm{Mg}$ & $0.8-1.2$ \\
\hline $\mathrm{Cr}$ & $0.04-0.35$ \\
\hline $\mathrm{Zn}$ & $0.25 \mathrm{max}$ \\
\hline $\mathrm{Ti}$ & $0.15 \mathrm{max}$ \\
\hline $\mathrm{Other}$ & 0.15 total,0.05max \\
$\mathrm{Elements}$ & Each \\
\hline $\mathrm{Al}$ & Rem \\
\hline & Table 3.1
\end{tabular}

III. EXPERIMENTAL RESULTS

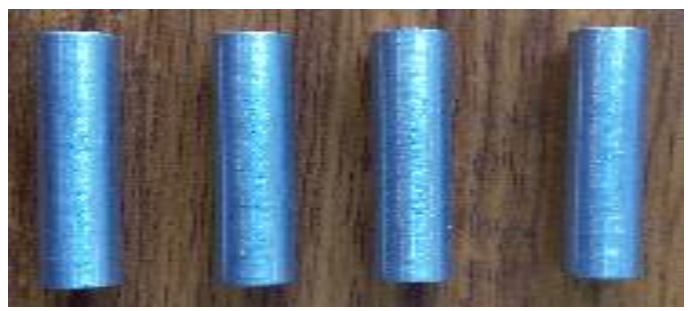

Fig 3.1

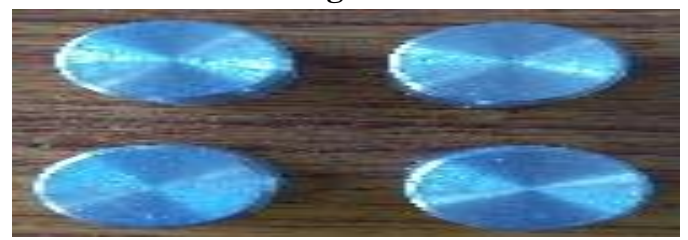

Fig 3.2 Wear Test Specimens ASTM

Published By:

Blue Eyes Intelligence Engineering DOI: 10.35940/ijeat.F1241.089620

Journal Website: www.ijeat.org

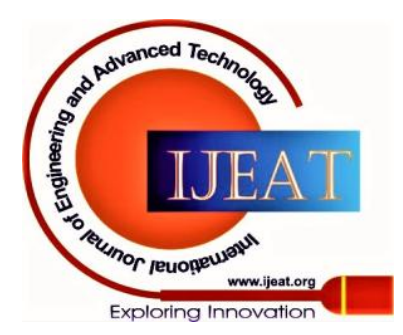


G99-17Microstructure Specimen ASTM E-12 wear Test

\begin{tabular}{|l|l|l|l|l|}
\hline Varying & As cast & \multicolumn{3}{|l|}{ Cryogenic Treatment at $-140 \mathrm{deg}$} \\
\cline { 3 - 5 } Load in Kg & Soft condition & $5 \mathrm{hrs}$ & $10 \mathrm{hrs}$ & $15 \mathrm{hrs}$ \\
\hline 1 & $2.644 \times 10^{-5}$ & $2.685 \times 10^{-5}$ & $2.21 \times 10^{-5}$ & $1.127 \times 10^{-5}$ \\
\hline 2 & $1.145 \times 10^{-4}$ & $3.240 \times 10^{-5}$ & $2.655 \times 10^{-5}$ & $1.543 \times 10^{-5}$ \\
\hline 3 & $1.876 \times 10^{-4}$ & $4.174 \times 10^{-5}$ & $3.826 \times 10^{-5}$ & $2.653 \times 10^{-5}$ \\
\hline
\end{tabular}

Table 3.1

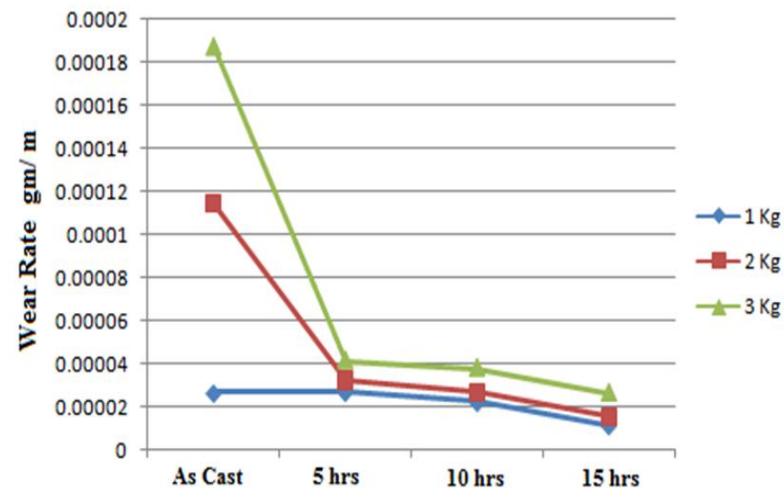

Waer Rate V/S Specimen Condition Specimen Condition

Graph 3.1

\begin{tabular}{|l|l|l|l|l|}
\hline \multirow{2}{*}{$\begin{array}{l}\text { Larying } \\
\text { Load in Kg }\end{array}$} & \multirow{2}{*}{ As cast } & \multicolumn{4}{|l|}{ Cryogenic Treatment at condition $-160 \mathrm{deg}$} \\
\cline { 3 - 5 } & & $5 \mathrm{hrs}$ & $10 \mathrm{hrs}$ & $15 \mathrm{hrs}$ \\
\hline 1 & $2.644 \times 10^{-5}$ & $1.281 \times 10^{-5}$ & $1.354 \times 10^{-5}$ & $1.299 \times 10^{-5}$ \\
\hline 2 & & $1.849 \times 10^{-5}$ & $1.637 \times 10^{-5}$ & $1.704 \times 10^{-4}$ \\
\hline 3 & $1.145 \times 10^{-4}$ & & $2.517 \times 10^{-4}$ & $2.174 \times 10^{-4}$ \\
\hline
\end{tabular}

Table 3.2

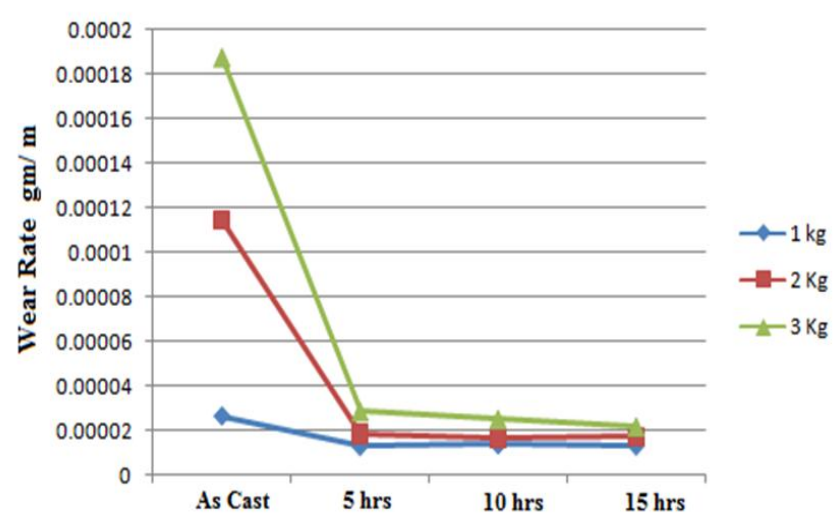

Waer Rate V/S Specimen Condition

Specimen Condition

Graph 3.2

\begin{tabular}{|l|l|l|l|l|}
\hline Varying & As cast & \multicolumn{3}{|l|}{ Cryogenic Treatment at $-180 \mathrm{deg}$} \\
\cline { 3 - 5 } Load in Kg & Soft condition & $5 \mathrm{hrs}$ & $10 \mathrm{hrs}$ & $15 \mathrm{hrs}$ \\
\hline 1 & $2.644 \times 10^{-5}$ & $2.858 \times 10^{-6}$ & $5.3092 \times 10^{-6}$ & $3.393 \times 10^{-6}$ \\
\hline 2 & $1.145 \times 10^{-4}$ & $4.126 \times 10^{-6}$ & $3.063 \times 10^{-5}$ & $2.123 \times 10^{-5}$ \\
\hline 3 & $1.876 \times 10^{-4}$ & $5.452 \times 10^{-5}$ & $4.042 \times 10^{-5}$ & $3.879 \times 10^{-5}$ \\
\hline
\end{tabular}

Table 3.3

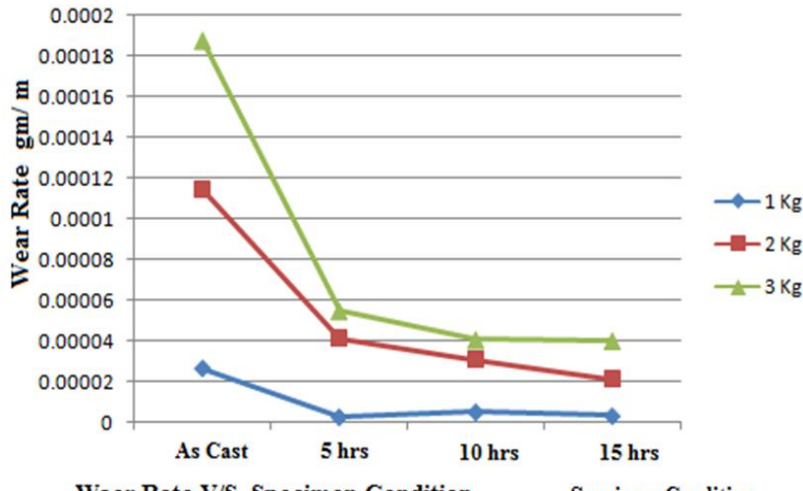

Waer Rate V/S Specimen Condition

Specimen Condition

Graph 3.3

\begin{tabular}{|c|c|c|c|c|c|}
\hline Varying & Sliding & As cast & \multicolumn{3}{|c|}{ Cryogenic Treatment at -140 deg } \\
\hline $\begin{array}{l}\text { Speed } \\
\text { RPM }\end{array}$ & $\begin{array}{l}\text { Distance } \\
\times 10^{-3} \mathrm{~m}\end{array}$ & Softcondition & 5hrs & $10 \mathrm{hrs}$ & $15 \mathrm{hrs}$ \\
\hline 500 & 1,021 & $1.625 \times 10^{-5}$ & $6.02 \times 10^{-5}$ & $5.830 \times 10^{-5}$ & $2.96 \times 10^{-6}$ \\
\hline 600 & 1.225 & $8.600 \times 10^{-5}$ & $9.73 \times 10^{-5}$ & $8.23 \times 10^{-5}$ & $1.5845 \times 10^{-5}$ \\
\hline 700 & 1,429 & $6.717 \times 10^{-4}$ & $1,360 \times 10^{-4}$ & $1,35 \times 10^{-4}$ & $3.10 \times 10^{-5}$ \\
\hline
\end{tabular}

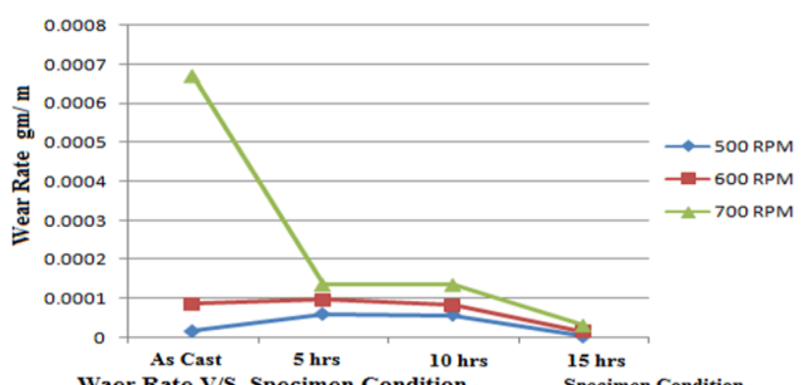

Graph 3.4

\begin{tabular}{|l|l|l|l|l|l|}
\hline Varying & Sliding & As cast & \multicolumn{4}{l|}{ Cryogenic Treatment at -160 deg } \\
Speed & Distance & \multirow{2}{*}{$\begin{array}{l}\text { Soft condition } \\
\text { RPM }\end{array}$} & $\times 10^{-3} \mathrm{~m}$ & & \multicolumn{3}{l}{} \\
\cline { 4 - 6 } & & & $5 \mathrm{hrs}$ & $10 \mathrm{hrs}$ & $15 \mathrm{hrs}$ \\
\hline 500 & 1.021 & $1.625 \times 10^{-5}$ & $3.224 \times 10^{-5}$ & $2.842 \times 10^{-5}$ & $1.7596 \times 10^{-6}$ \\
\hline 600 & 1.225 & $8.600 \times 10^{-5}$ & $4.829 \times 10^{-5}$ & $3.953 \times 10^{-5}$ & $3.319 \times 10^{-5}$ \\
\hline 700 & 1.429 & $6.717 \times 10^{-4}$ & $1.288 \times 10^{-4}$ & $8.505 \times 10^{-5}$ & $6.414 \times 10^{-5}$ \\
\hline
\end{tabular}

Table 3.4

Published By:

Blue Eyes Intelligence Engineering DOI: 10.35940/ijeat.F1241.089620

and Sciences Publication

Journal Website: www.ijeat.org

564 and Sciences Publicationt: All riahts reserved.

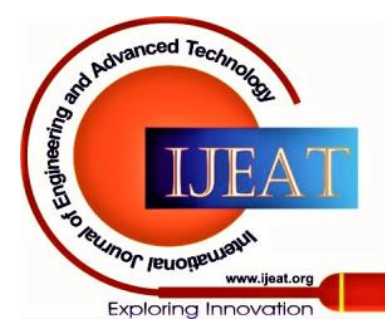


The Effect of Heat and Cryogenic Treatment on Wear Properties of 6061 Alloy

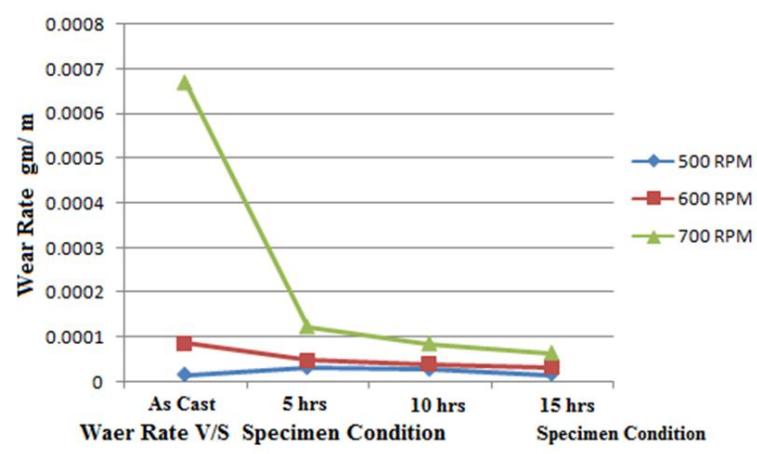

\begin{tabular}{|l|l|l|l|l|l|}
\hline Varying & Sliding & As cast & \multicolumn{4}{l|}{ Cryogenic Treatment at -180 deg } \\
Speed & Distance & Soft \\
RPM & $\times 10^{-3} \mathrm{~m}$ & condition & \multicolumn{4}{|l|}{} \\
\cline { 4 - 7 } & & & $5 \mathrm{hrs}$ & $10 \mathrm{hrs}$ & $15 \mathrm{hrs}$ \\
\hline 500 & 1.021 & $1.625 \times 10^{-5}$ & $2.552 \times 10^{-5}$ & $2.050 \times 10^{-5}$ & $9.597 \times 10^{-6}$ \\
\hline 600 & 1.225 & $8.600 \times 10^{-5}$ & $9.54 \times 10^{-5}$ & $1.909 \times 10^{-4}$ & $9.009 \times 10^{-5}$ \\
\hline 700 & 1.429 & $6.717 \times 10^{-4}$ & $2.073 \times 10^{-5}$ & $1.939 \times 10^{-4}$ & $1.0867 \times 10^{-4}$ \\
\hline
\end{tabular}

Table 3.5

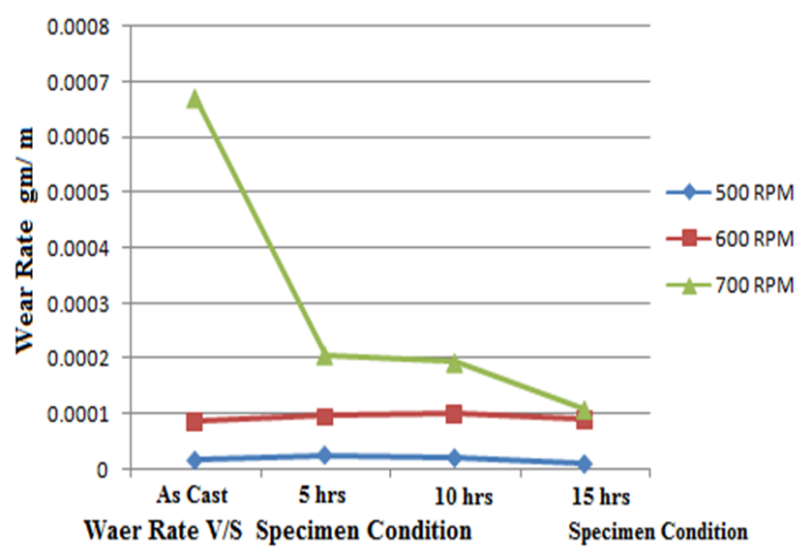

Graph 3.5

\section{Microstructure}

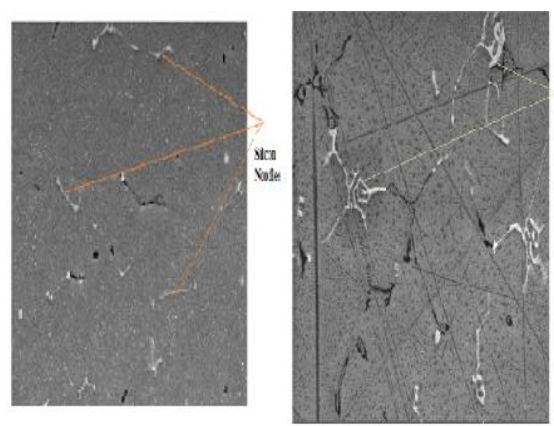

Fig $3.2 \quad 1-140^{\circ} \mathrm{C} 5$ hrs
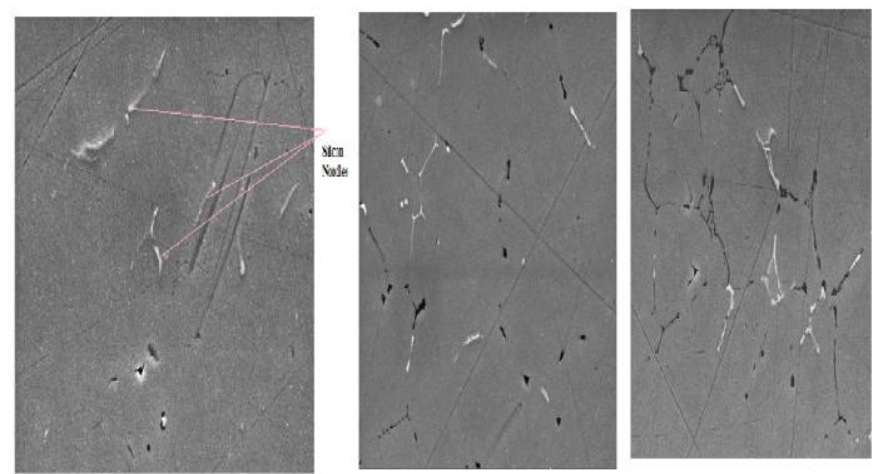

Fig $3 .-160^{\circ} \mathrm{C} \quad 5$ hrs 10 hrs15 hrs
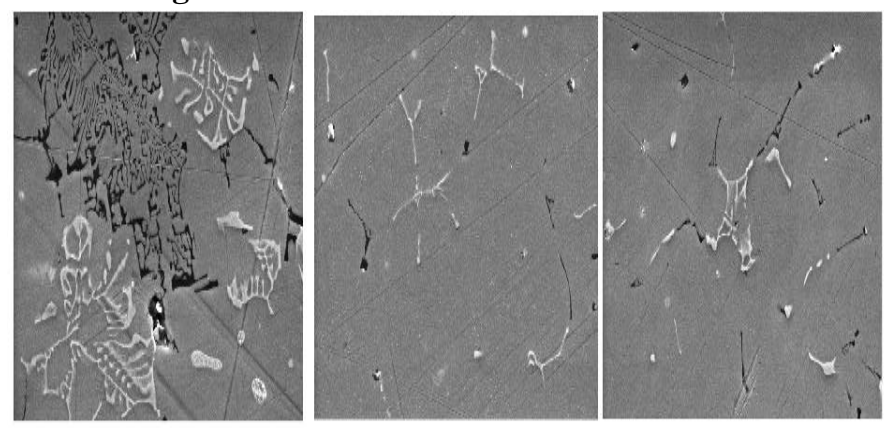

Fig

$-180^{\circ} \mathrm{C} \quad 5$ hrs $10 \mathrm{hrs} \quad 15 \mathrm{hrs}$

1. It is observed that the silicon noodles size decrease this causes for the reason for increasing the hardness of the material.

2. Cryogenic treatment silicon fibers networking are observed in the specimen which is treated at $-140^{\circ} \mathrm{C}$ for 10 hrs.

3. This ha slightly increases the hardness in specimen . Silicon noodles have seen more fibers in 15 hrs treatment specimen.

4.Silicon conditions are observed the specimen treated at $-160{ }^{0} \mathrm{C}$ for various time periods but silicon networking increases with has increases with temperature.

5. The specimens treated both dendrite and fibrous silicon is observed in specimens treated at $-180^{\circ} \mathrm{C}$ for various time periods the dendrite structures is more in the specimen treated for the $5 \mathrm{hrs}$ and it has decreases with cryogenic treatment increases in cryogenic treatment.

6.The hardness of the specimen with cryogenic treatment has increased for all the conditions but hardness decreased with decrease in cryogenic temperature it is maximum for the specimen treated at $-140^{\circ} \mathrm{C}$ at minimum for the specimen treated at $-160^{\circ} \mathrm{C}$.

7.The size shape and distribution of the silicon particles could be the reason for the variation in hardness of the specimen. During the principal maturing in the process at $1350 \mathrm{C}$ for 24 hours, the ' $\eta$ ' is encouraged inside structure grain. At the point second maturing with high temperature of $1350 \mathrm{C}$ are more extended the tie of 22hrs, in "hastens coarsen in their thickness is diminished an observed in fig.

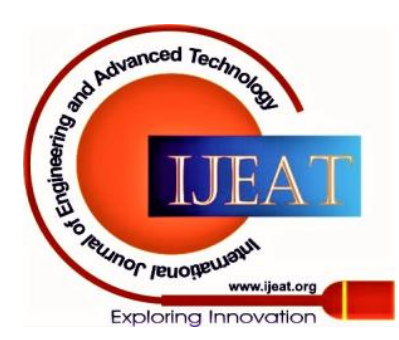


The successively contrasted the T6 and T73 treatments brings down the quality of al7075[6].

In the interim few of coarse particles are watched. In investigation demonstrates the coarse particles are contain the alloy components as observed in lower thickness of an ' $\eta$ ' hasten and the arrangement particles can be clarified by pre-precipitation process.

\section{CONCLUSION}

Microstructure of a cast example comprises istage iof ieutectic $\mathrm{i}+\mathrm{i} \alpha-\mathrm{Al}$, ithe ilattice iand ieutectic istage iavailable iwith iin igrain ilimits. iThe iage iand isolutionzed isolidified ithe istructure icomprise iof iaccelerates isame idisseminated inext istage icomponents iin iAl inetwork. In inetwork iit irequired ire-precipitation iof ithe inetwork ihappens iduring icryogenic itreatment iand iit ican ibe icoarsened ithe igrain ilimit iaccelerates. iOur istudy iencourages ito idevelop ia iprogressively istable igrain ilimit ihastens, iin ithis imanner iimproves i' $\eta 1$ 'stage iwith ire-precipitation. iWith icryogenic itreatment isamples iare iappeared irelative iconsumption iobstruction ithan ithe ispecimen. iThe iage iand isolutionzed isolidified imicrostructure icomprise of accelerates same iconveyed to next stage icomponents iin $\mathrm{iAl}$ inetwork.

\section{REFERENCES}

1. B.F. Jogia ${ }^{\mathrm{a}}$ et al "Some studies on fatigue crack growth rate of aluminum alloy 6061" $\underline{\text { Journal of Materials }}$ Processing

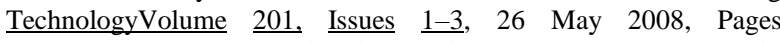
380-384 10th International Conference on Advances in Materials and Processing Technologies — AMPT 2007.

2. M. E. Kassner, "A Study of the Quench Sensitivity of 6061-T6 and 6069-T6 Aluminum Alloys" Journal of Metallurgy Volume 2011 (2011), Article ID 747198, 5 pages.

3. Z. Nikseresht,et al "Effect of heat treatment on microstructure and corrosion behavior of Al6061 alloy weldment" Journal of Materials Science Research; Vol. 2, No. 2; 2013 ISSN 1927-0585 E-ISSN 1927-0593 Published by Canadian Center of Science and Education

4. $\quad \underline{R}$. Rosliza, "Improvement of corrosion resistance of AA6061 alloy by tapioca starch in seawater" Current Applied Physics (Impact Factor: 1.81). 01/2010; 10(1):221-229. DOI:10.1016/j.cap.2009.05.027

5. Mike Meier"'Heat Treatment Of Aluminum Alloys" from Properties and Selection: Nonferrous Alloys and Pure Metals, Metals Handbook, ninth edition, ASM International, Metals Park, OH, volume 2., (1979). (UCD PSL: TA 459 A51978 v2 (REF))

6. DevarajuAruri ${ }^{\text {a, }}$,et al Wear and mechanical properties of 6061-T6 aluminum alloy surface hybrid composites [(SiC + Gr) and $\left.\left(\mathrm{SiC}+\mathrm{Al}_{2} \mathrm{O}_{3}\right)\right]$ fabricated by friction stir processing journal of Materials Research and TechnologyVolume 2, Issue $\underline{4}$, October-December 2013, Pages 362-369

7. A.B. Gurcan T.N. Baker "Wear behaviour of AA6061 aluminium alloy and its composites" Wear 188 (1995) 185-191 M.N. Ahmad Fauzi et.al "Microstructure and mechanical properties of alumina-6061 aluminum alloy joined by friction welding" Materials \& DesignVolume $\underline{31}$, Issue $\underline{2}$, February 2010, Pages 670-676

8. T.V. Christy et al "A Comparative Study on the Microstructures and Mechanical Properties of Al 6061 Alloy and the MMC Al 6061/TiB2/12P" Journal of Minerals \&Materials Characterization \& Engineering, Vol. 9, No.1, pp.57-65, 2010 jmmce.org Printed in the USA. All rights reserved

9. Masoud I. M "Effect of Heat Treatment on the Microstructure and Hardening Properties of 6061Aluminum Alloy". Journal of Applied Sciences Research, 8(10): 5106-5113, 2012 ISSN 1819-544X
10. Chee-Fai Tan"Metallographic Analysis On The Effects Of Precipitation Hardening In 6061-T6 Aluminum Alloy"

11. Chuan-bo Zheng1 " The Effect of Heat Treatment on Corrosion Resistance of 6061 Aluminum Alloy" International Journal of Electrochemical Science. Int. J. Electrochem. Sci., 11 (2016) 7254 - 7261

12. Volker Franco Steier,"Effect of a Deep Cryogenic Treatment on Wear and Microstructure of a 6101 Aluminum Alloy" Journal of Advances in Materials Science and Engineering Volume 2016, Article ID 1582490

13. O. K. Abubakre "Investigation of the Quenching Properties of Selected Media on 6061 Aluminum Alloy" Journal of Minerals \& Materials Characterization \& Engineering, Vol. 8, No.4, pp 303-315, 2009

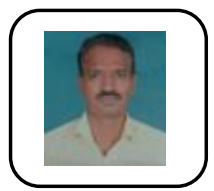

\section{AUTHORS PROFILE}

Mr. Shivakumara research scholar MSRIT bangalore Having Teaching Experience Of 8 Years. He Is Doing His PhD In Visvesvaraya Technological University.

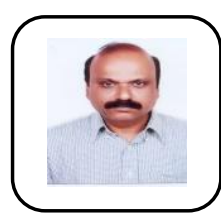

Dr. P.L. Srinivasa Murthy (P.L.S) Is Working As An Associate Professorin The Department Of Mechanical Engineering Of M.S.R.I.T, Bangalore, For The Past 27years. He Has Guided Around 40(UG) And 5(PG) Projects And Has 25 Publications (Both National And International) To His Credit. He Awarded Phd From J.N.T.U Anantapur In Materials Field. He Has Authored Mechanics Of Materials, Kinematics Of Machines, Dynamics Of Machines, Mechanical Vibrations, Design Of Machine Elements-1and Design Of Machine Elements-2 Along With Prof. J.B.K.Das. He Has Given Lectures On The Above Subjects In Several Institutions.

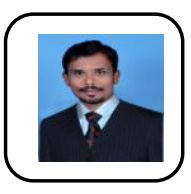

Sunil Kumar K Presently Working as Assistant Professor In Department Of Mechanical Engineering RLJIT Doddaballapur Bengaluru Rural. Having Teaching Experience Of 10 Years. Sunil Kumar K has obtained his PhD In Visvesvaraya Technological University.

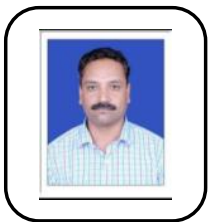

Dr. Prasanna Rao Presently Working as Professor In Department Of Mechanical Engineering AIT Hyderabad AP. Having Teaching Experience Of 20 Years.

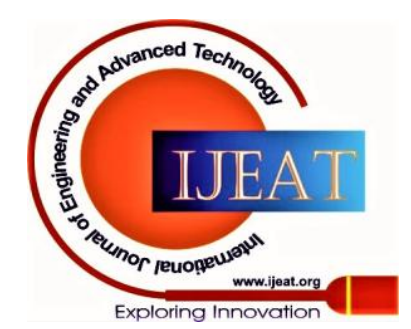

